Document downloaded from:

http://hdl.handle.net/10251/99612

This paper must be cited as:

Moliner Marin, M.; Corma Canós, A. (2012). Direct synthesis of a titanosilicate molecular sieve containing large and medium pores in its structure. Microporous and Mesoporous Materials. 164:44-48. doi:10.1016/j.micromeso.2012.06.035

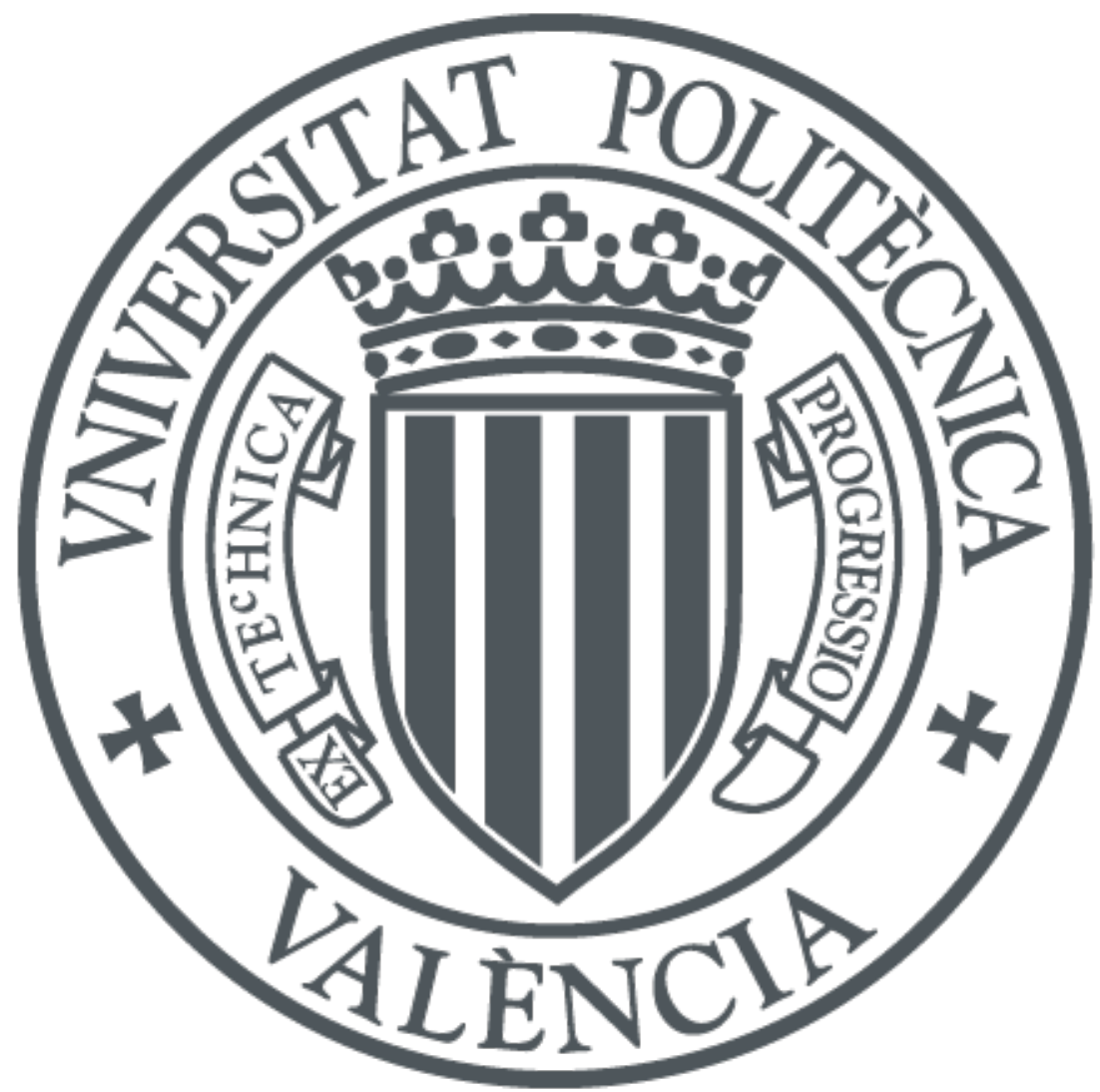

The final publication is available at

https://doi.org/10.1016/j.micromeso.2012.06.035

Copyright Elsevier

Additional Information 


\title{
Direct synthesis of a titanosilicate molecular sieve containing large and medium pores in its structure
}

\author{
Manuel Moliner, Avelino Corma* \\ Instituto de Tecnología Química (UPV-CSIC), Universidad Politécnica de Valencia, Consejo Superior de \\ Investigaciones Científicas, Valencia, 46022, Spain \\ * Corresponding author: E-mail address: acorma@itq.upv.es. Postal address: Av. de los Naranjos s/n, \\ 46022 Valencia, Spain. Tel.: 3496 3877800, Fax: 34963879444 \\ Dedicated to Professor Jens Weitkamp on his $70^{\text {th }}$ birthday
}

\begin{abstract}
The direct synthesis of the titanosilicate form of ITQ-39 is reported. This is the first description of the direct preparation of a titanosilicate molecular sieve containing large and medium pores in the same structure. The characterization clearly indicates the presence of $\mathrm{Ti}$ atoms in tetrahedral coordination in the framework of ITQ-39 zeolite. This material is very active in the oxidation of lineal and cyclic olefins with $\mathrm{H}_{2} \mathrm{O}_{2}$, showing selectivities between TS- 1 and Ti-Beta.
\end{abstract}

\section{Highlights}

- Direct synthesis of a titanosilicate containing large and medium pores.

- Efficient catalyst in the selective oxidation of lineal and cyclic olefins.

- Other metallosilicate forms of ITQ-39 would be prepared by direct synthesis. 
Graphical abstract

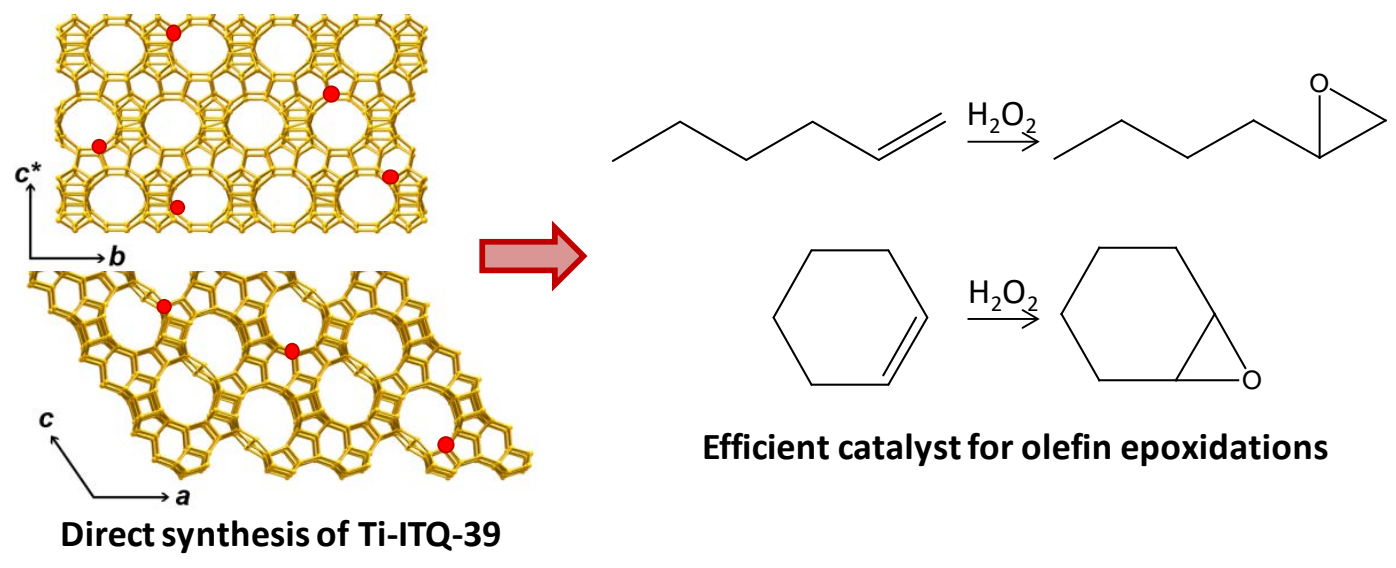




\section{1.- Introduction}

The synthesis of molecular sieves containing interconnected different sized pores in the same structure can be very useful in catalysis since they would allow different diffusion rates of molecules along them, introducing remarkable changes in the product selectivities.[1] In this sense, diverse silicoaluminate molecular sieves with different sized pores have been successfully reported in the last years, showing unique catalytic behaviors.[2] Probably, the most outstanding materials are those containing large and medium pores in the same structure, due to the attractive industrial catalytic implications that those channel topologies introduce in several acid processes. Some interesting examples are $\mathrm{CIT}-1$, which is an attractive additive catalyst in cracking reactions, since produces large ratios of $\mathrm{i}-\mathrm{C} 4 / \mathrm{n}-\mathrm{C} 4$ and $\mathrm{i}-\mathrm{C} 5 / \mathrm{n}$ C5;[3] MCM-68, which shows higher propylene selectivity in comparison with other zeolites, allowing its application as FCC additive for highly selective propylene production;[4] and ITQ39, which is a very active and stable catalyst for the conversion of naphta into diesel by alkylation.[5]

Other transition elements, such as titanium, have been successfully introduced as isolated tetrahedral framework species in some zeolites, and those titanosilicate materials have been extensively applied as very selective catalysts for relevant oxidation reactions.[6] Several titanosilicates have been described in the literature (such as TS-1,[7] Ti-Beta,[8] Ti-ZSM-12,[9] Ti-MOR,[10] Ti-ITQ-7,[11] Ti-MWW,[12] or Ti-BEC,[13] among others), but only two examples of titanosilicates show large and medium pores in the same structure, Ti-SSZ-33 [14] and TiMCM-68.[15] In those materials, $\mathrm{Ti}$ atoms can only be introduced by post-synthetic methodologies, due to both materials are prepared as borosilicate, SSZ-33, or aluminosilicate, MCM-68. Indeed, post-synthetic treatments are required for selectively removing B or Al framework atoms, followed by additional steps to introduce isolated $\mathrm{Ti}$ atoms in the framework. In the case of SSZ-33, Davis et al. described a procedure based on three steps: first, 
the calcined sample was treated with $\mathrm{Ar}$ at $300^{\circ} \mathrm{C}$; second, the Ar flow was bubbled through a vessel containing $\mathrm{TiCl}_{4}$, and third, the argon stream was bubbled through methanol.[14] They claimed that the methanol allows the removal of boron atoms by producing volatile trimethyl borate, and then, titanium is inserted in the vacancy created. In the case of MCM-68, Tatsumi et al. [15] removed the framework $\mathrm{Al}$ atoms by acid treatments followed by gas-phase $\mathrm{Ti}$ insertion using $\mathrm{TiCl}_{4}$.

Those post-synthetic methodologies on SSZ-33 and MCM-68 are effective for preparing the titanosilicate form of zeolites containing large and medium pores in the same structure, but the numerous steps required for their preparation result in an unproductive synthetic process. Moreover, the complete elimination of boron or aluminium from the framework or from the pores is not always possible and side reactions towards undesired by-products could also occur.

Recently, a new zeolite containing interconnected large and medium pores, ITQ-39, has been reported.[5,16] This novel material can be synthesized under broad synthesis conditions, even as pure silica polymorph, opening a very attractive route towards the direct preparation of a titanosilicate molecular sieve with interconnected large and medium pores.

Herein, we will show the direct synthesis of the titanosilicate form of ITQ-39 zeolite. This material will be properly characterized, showing the presence of isolated tetrahedral Ti species in the zeolite framework. Finally, its catalytic properties will be tested in the selective epoxidation reactions of two different sized olefins, revealing the presence of single active Ti species in both channel systems. This direct synthesis route towards the preparation of the titanosilicate ITQ-39 would open an attractive synthesis methodology for preparing other metallosilicate forms of this material, offering new promising active catalysts containing large and medium pores in the same structure that would introduce unique product selectivities in fine chemistry or biomass transformations.[17] 


\section{2.- Experimental}

\section{1.- Organic structure directing agent (OSDA) synthesis}

The OSDA cation required for the synthesis of the titanosilicate form of ITQ-39 was prepared as follows: $30 \mathrm{~g}$ of pyrrolidine (Sigma-Aldrich, 99\%) was dissolved in $200 \mathrm{~mL}$ of methanol (Sigma-Aldrich, $>99 \%$ ). The solution was acidified with $\mathrm{HCl}$ (Fluka, $5 \mathrm{~N}$ in methanol) until $\mathrm{pH}=$ 7.5, cooling the mixture at $273 \mathrm{~K}$. Next, $37 \mathrm{~g}$ of 1-propyl-4-piperidone (Sigma-Aldrich, 99\%) was added, followed by $10.5 \mathrm{~g}$ of sodium cyanoborohydride $\left(\mathrm{NaBH}_{3} \mathrm{CN}\right.$, Fluka, $\left.>95 \%\right)$. The resultant mixture was stirred during $72 \mathrm{~h}$ at room temperature.

After that, $\mathrm{HCl}$ was added slowly until reaching a $\mathrm{pH}$ close to 2, removing the $\mathrm{HCN}$ formed by flowing nitrogen. The solution was concentrated, and a $25 \%$ wt aqueous solution of $\mathrm{KOH}$ was added until $\mathrm{pH}>12$, achieving then a white precipitate. The mixture was saturated with $\mathrm{NaCl}$, and the diamine 1-propyl-4-pyrrolidin-1-yl-piperidine was extracted with diethyl ether.

$20 \mathrm{~g}$ of the diamine 1-propyl-4-pyrrolidin-1-yl-piperidine was diluted in $70 \mathrm{ml}$ of $\mathrm{NaOH}$, and then $60 \mathrm{~g}$ of ethyl iodide was added dropwise. After 7 days under stirring at room temperature, a white precipitate was obtained, which was filtered and washed with methanol and diethyl ether. Finally, the solid was dried under high vacuum.

The iodide form of the organic salt was exchanged to the hydroxide form as follows: $44 \mathrm{mmol}$ of cation in the iodide form was dissolved in water, and $89 \mathrm{~g}$ of Dower-SBR Anion Exchange resin in hydroxide form (total exchange capacity 1.4 eq/l) was added, maintaining under agitation overnight. The solution was filtered, and the dihydroxide cation was obtained.

\section{2.- Zeolite syntheses}

Ti-ITQ-39 was synthesized as follows: $6.03 \mathrm{~g}$ of an aqueous solution of OSDA in hydroxide form (9.9\%wt) was mixed with $1.73 \mathrm{~g}$ of tetraethyl orthosilicate (TEOS, Sigma-Aldrich, 99\%wt). After 
30 minutes of stirring, $47 \mathrm{mg}$ of titanium (IV) isopropoxide (TilSO, Sigma-Aldrich, 99\%wt) was introduced. The mixture was maintained under stirring until complete hydrolysis of TEOS and TilSO. Then, $0.17 \mathrm{~g}$ of hydrofluoric acid (Sigma-Aldrich, $48 \% \mathrm{wt}$ ) was added to the gel, and the gel was stirred until evaporation of the excess of water. The final gel molar composition was fixed as: $\mathrm{SiO}_{2}: 0.02 \mathrm{TiO}_{2}: 0.25 \mathrm{OSDA}(\mathrm{OH})_{2}: 0.50 \mathrm{HF}: 3 \mathrm{H}_{2} \mathrm{O}$. The gel was transferred to $10 \mathrm{ml}$ Teflon lined autoclave and heated at $135{ }^{\circ} \mathrm{C}$ for 30 days. The resultant solids were filtered, washed, and dried at $100^{\circ} \mathrm{C}$.

Ti-Beta and TS-1 zeolites were synthesized following the procedures described in the literature.[18]

The as-prepared samples were calcined in air at $580^{\circ} \mathrm{C}$ for 6 hours.

Characterization.

Synthesized samples were characterized by powder X-ray diffraction (PXRD) using a multisample Philips X'Pert diffractometer equipped with a graphite monochromator, operating at $40 \mathrm{kV}$ and $45 \mathrm{~mA}$, and using Cu KR radiation $(\lambda=0.1542 \mathrm{~nm})$.

The chemical analysis was performed in a 715-ES ICP-Optical Emission spectrometer, after solid dissolution in $\mathrm{HNO}_{3} / \mathrm{HCl} / \mathrm{HF}$ aqueous solution. The organic content of the as-made materials was determined by elemental analysis performed on a SCHN FISONS elemental analyzer.

UV-vis spectra were obtained with a Perkin Elmer (Lambda 19) spectrometer equipped with an integrating sphere with $\mathrm{BaSO}_{4}$ as reference.

Catalytic tests.

Reactions were carried out in 2-mL glass flasks with magnetic stirring and heated by means of a temperature controlled aluminum rack. Catalytic tests by using $\mathrm{H}_{2} \mathrm{O}_{2}$ as oxidant were 
performed at $333 \mathrm{~K}$, using $20 \mathrm{mg}$ of catalyst and the following reaction mixture: $1.6 \mathrm{mmol}$ of olefin (1-hexene or cyclohexene), $0.4 \mathrm{mmol}$ of $\mathrm{H}_{2} \mathrm{O}_{2}, 1.2 \mathrm{~g}$ of solvent (methanol or acetonitrile). All substances were available from Sigma-Aldrich Company (Acetonitrile, 99\%; 1-hexene, 99\%; cyclohexene, 99\%; $\mathrm{H}_{2} \mathrm{O}_{2}, 35 \mathrm{wt} \%$ in water). Aliquots were analyzed online by gas chromatography using nonane as standard. $\mathrm{H}_{2} \mathrm{O}_{2}$ efficiency was calculated by iodemetric tritation.

\section{3.- Results}

ITQ-39 zeolite is a very complex structure formed by the intergrowth of three different polymorphs, all of them containing large and medium pores in their structures.[5] This material can be synthesized under very broad synthesis conditions depending on the OSDA used in its preparation.[16] When the OSDA introduced in the synthesis media contains a combination of ethyl and propyl groups (see Figure 1), the pure silica form of ITQ-39 can be achieved. Interestingly, this pure silica ITQ-39 can be obtained in the absence of alkali cations, such as potassium or sodium. This is an important point for attempting the isomorphic substitution of titanium atoms in the zeolite framework, since those cations preclude the insertion of isolated titanium in the framework due to the precipitation of alkali titanates during the synthesis process.[19] Then, we attempted the synthesis of the titanosilicate form of ITQ-39 under similar conditions to the pure silica ITQ-39, using the same OSDA (see Figure 1), working in fluoride media and very concentrated gels (water to silicon rations lower than 3 ) at 135 ․ C. The silicon to titanium ratio in the gel was fixed on 50. The fully-crystalline titanosilicate ITQ-39 was achieved after 30 days (see PXRD pattern in Figure 2), while the pure silica polymorph was obtained after 14 days.[16] The increase of crystallization times when titanium atoms are introduced in the synthesis media has been widely reported in the literature.[20] 
Chemical analyses on the crystalline Ti-ITQ-39 (see Table 1) indicate a silicon to titanium ratio in the final solid of $163\left(0.81 \% \mathrm{wt} \mathrm{TiO}_{2} / \mathrm{SiO}_{2}\right)$. In order to properly identify the coordination of Ti species in the titanosilicate ITQ-39, the calcined sample was studied by UV-visible spectroscopy. As seen in Figure 3, a unique band at $220 \mathrm{~nm}$, assigned to isolated Ti species in the zeolite framework,[21] is observed on the calcined Ti-ITQ-39.

Ti-ITQ-39 was also studied by scanning electron microscopy (SEM), and as seen in Figure 4A, large crystals $(5 \times 1 \mu \mathrm{m})$ with rectangular morphology were obtained. The achievement of large sized-crystals is characteristic of high-silica zeolites synthesized in fluoride media.[22]

The presence of isolated Ti species in the ITQ-39 framework, which contains connected large and medium pores, would allow its application as catalyst in several selective oxidation reactions, such as selective oxidation of olefins. In order to compare the catalytic activity of TiITQ-39, other two titanosilicates were also prepared: the large pore Ti-Beta zeolite, and the medium pore TS-1 zeolite. Both materials were synthesized in fluoride media following procedures described in the literature,[18] with the aim to achieve similar crystal sizes to TiITQ-39.

PXRD patterns of those titanosilicates are shown in Figure 2, indicating their excellent crystallinity. Both materials were synthesized with large crystal sizes, 8-10 $\mu \mathrm{m}$ in the case of TiBeta, and 2-6 $\mu \mathrm{m}$ in the case of TS-1 (see Figure 4). Chemical analyses reveal a silicon to titanium ratio of 83 for Ti-Beta, and 33 for TS-1 zeolite (see Table 1). The coordination of Ti atoms was studied by UV-Vis spectroscopy (see Figure 3). A unique band centered at $220 \mathrm{~nm}$ is achieved for Ti-Beta, while a very intense band centered at $220 \mathrm{~nm}$ with a slight shoulder at $260 \mathrm{~nm}$ is accomplished for TS-1 material. This shoulder at $260 \mathrm{~nm}$ indicates the presence of small amount of octahedral Ti species, which are characteristic of polymeric extra-framework titanium species. 
Those three titanosilicate materials were first tested on the oxidation of 1-hexene with $\mathrm{H}_{2} \mathrm{O}_{2}$ in methanol (see Table 2). In terms of activity, 1-hexene reacts slightly faster on Ti-Beta catalyst than on Ti-ITQ-39, and both show much more activity than TS-1 (see initial rates per metal center and the consumed time to achieve similar conversion levels on Table 2). This can be explained by the lower steric restrictions found on zeolites containing large pores in their structure. However, the selectivity under similar levels of 1-hexene conversion towards the desired epoxide is almost $100 \%$ on TS-1, while Ti-ITQ-39 and Ti-Beta show $56 \%$ and $44 \%$ respectively. Other by-products, such as monomethylglycolethers (MGE) and glycols, can be observed on Ti-ITQ-39 and Ti-Beta. The presence of those by-products has been well documented in the literature of titanosilicates containing large pores, and they are primary produced by the ring opening of the formed epoxides with protic solvents.[23] Nevertheless, the intermediate epoxide selectivity on Ti-ITQ-39 when compared to TS-1 and Ti-Beta at similar conversion levels is an indication that both, medium and large pores of ITQ-39, contain isolated metal active centers capable to catalyze the transformation of 1-hexane molecules.

In order to avoid the formation of by-products by the nucleofilic attack of the protic solvent, 1hexene oxidation has also been studied using acetonitrile as solvent. As expected, the selectivies toward the epoxide product in acetonitrile are almost $100 \%$ for all three catalysts (see Table 3). In terms of activity, Ti-ITQ-39 catalyst shows intermediate initial reaction rates and also intermediate times to achieve similar conversion levels (see Table 3) when compared to Ti-Beta and TS-1. This intermediate activity can be explained by the presence of steric restrictions offered by the medium pores in Ti-ITQ-39 to reactants and products.

Further oxidation catalytic studies have been performed with a larger olefin, such as cyclohexene. As it can be seen in Figure 4, the selectivities to the epoxide product for all three titanosilicates are much lower than the obtained when 1-hexene was tested. This catalytic behavior is explained due to the higher stability of the oxirane group of the formed lineal 
epoxide than the cyclic, whose epoxide can be opened much easier.[24] Moreover, it has been widely described that cyclohexene can diffuse through large pores, but suffers severe restrictions when diffusing through medium pores.[25] Indeed, TS-1 shows the lowest activity in the oxidation of cyclohexene (see initial rates per active center on Table 4), and also the lowest selectivity to the epoxide product, probably because the reaction is taking place on the external surface. Interestingly, the most active material on the oxidation of cyclohexene is TiITQ-39 (see initial rates and time to achieve similar conversion levels in Table 4), despite that the presence of medium pores in Ti-ITQ-39 may impose higher diffusion limitations than the exclusively large pores in Ti-Beta. A possible explanation of this unexpected higher activity of Ti-ITQ-39, could be the presence of larger crystal sizes in Ti-Beta compared to Ti-ITQ-39, whose crystals are much thinner and then diffusion problems would be diminished.

Then, the high activity showed by Ti-ITQ-39 zeolite in the oxidation of olefins, together with the different product selectivities obtained when compared to Ti-Beta and TS-1, would permit its potential use as an efficient catalyst performing unique selectivities in other attractive catalytic applications where isolated Lewis acid active sites are required.

\section{4.- Conclusions}

A new titanosilicate molecular sieve, Ti-ITQ-39, containing large and medium pores in its structure has been prepared by a direct synthesis methodology. This is the first example of a titanosilicate with connected large and medium pores that has been synthesized directly, avoiding highly undesired post-synthetic treatments. The characterization performed on TiITQ-39 clearly indicates that Ti atoms are in tetrahedral coordination in the zeolite framework. This material is very active in the oxidation of lineal and cyclic olefins with $\mathrm{H}_{2} \mathrm{O}_{2}$, showing unique selectivities to products when compared to Ti-Beta (pure large pores) and TS-1 (medium large pores). The results obtained would allow the use of Ti-ITQ-39 in other attractive catalytic applications on fine chemistry or biomass transformations. 


\section{Acknowledgment}

Financial support by the Spanish MEC (Consolider Ingenio 2010-Multicat), Generalitat Valenciana by the PROMETEO program and UPV through PAID-06-11 (n.1952) is acknowledged. Manuel Moliner acknowledges to "Subprograma Ramon y Cajal" for the contract RYC-2011-08972. Jose Gaona is also acknowledged for technical help. 
Figure 1: OSDA used in the synthesis of the titanosilicate form of ITQ-39

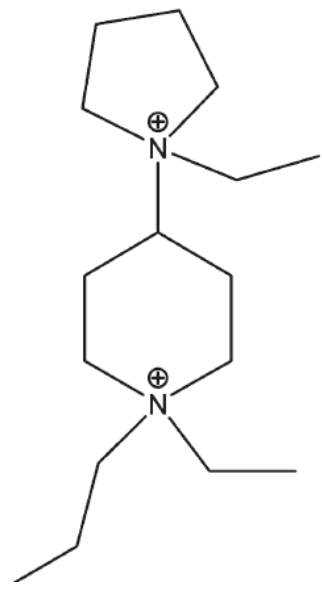


Figure 2: PXRD patterns of Ti-ITQ-39, Ti-Beta and TS-1

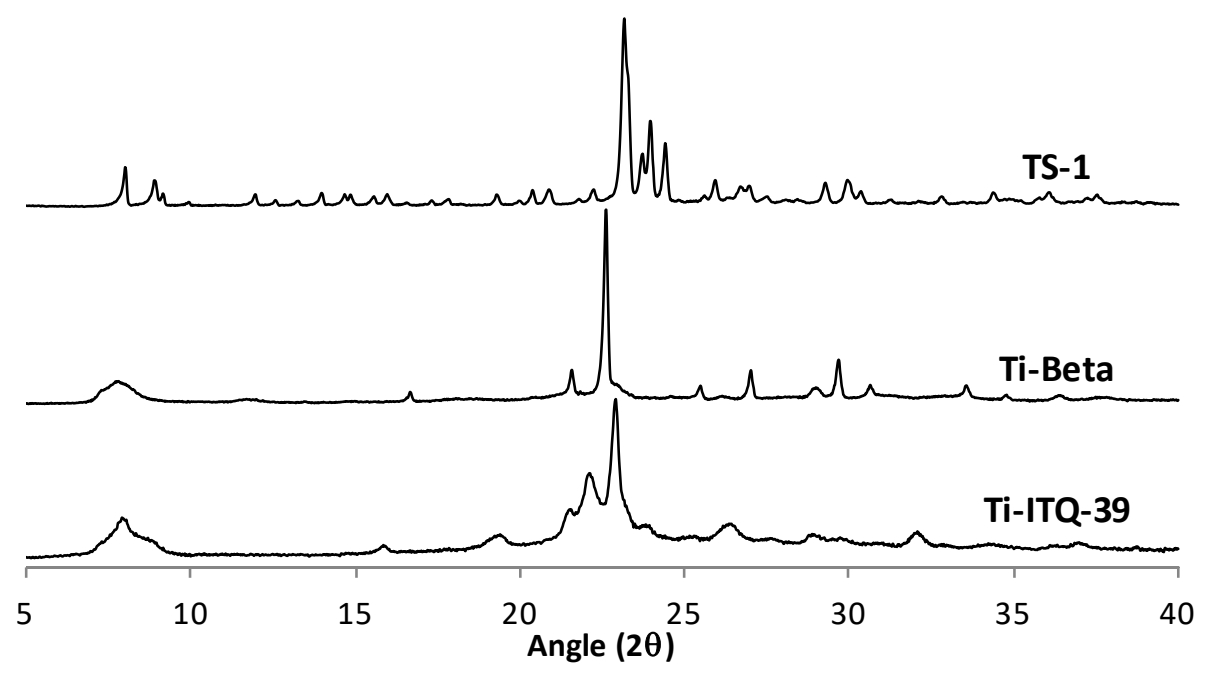


Figure 3: UV-Vis DRS spectra of calcined titanosilicates

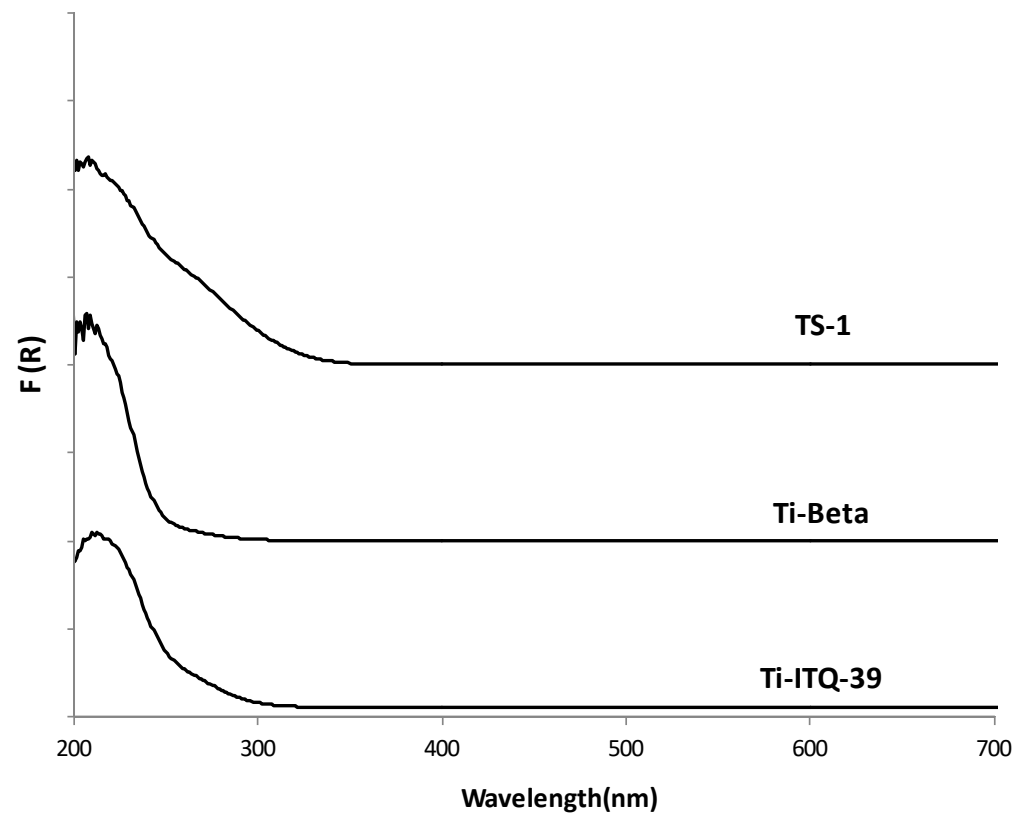


Figure 4: SEM images of Ti-ITQ-39 (A), Ti-Beta (B) and TS-1 (C)

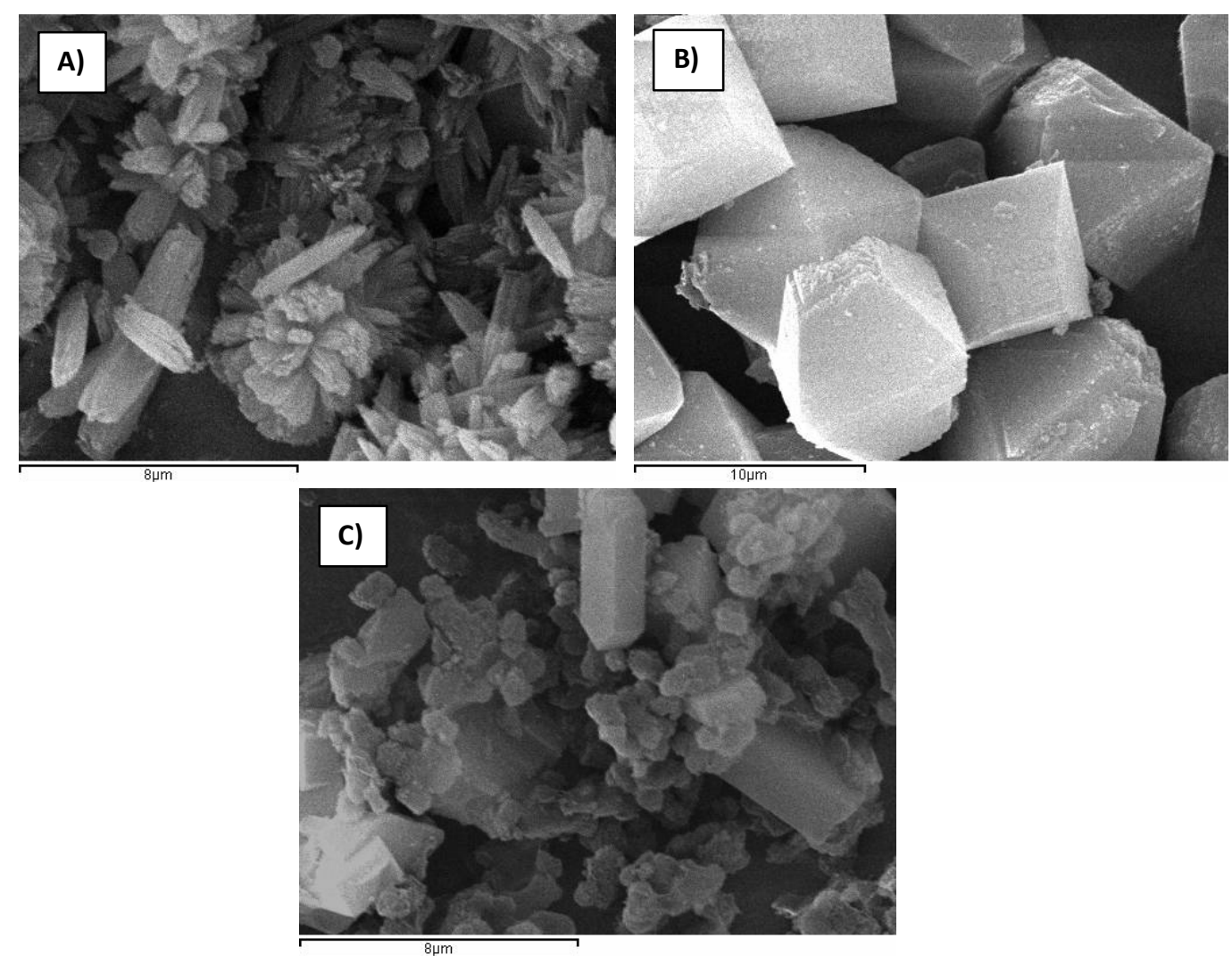


Tables

Table 1: Chemical analyses and crystal sizes of the different titanosilicates

\begin{tabular}{ccc} 
Sample & Si/Ti & Crystal size $(\boldsymbol{\mu m})$ \\
\hline Ti-ITQ-39 & 163 & $5 \times 1$ \\
Ti-Beta & 83 & $8-10$ \\
TS-1 & 33 & $2-6$
\end{tabular}

Table 2: Oxidation of 1-hexene with $\mathrm{H}_{2} \mathrm{O}_{2}$ in methanol over different titanosilicates

Selectivity (\%)

\begin{tabular}{|c|c|c|c|c|c|c|c|}
\hline \multirow[b]{2}{*}{ Catalyst } & \multirow[b]{2}{*}{$r_{0}\left(\mathrm{~mol}_{\text {conv }} / \text { h. } \mathrm{mol}_{\mathrm{Ti}}\right)^{\mathrm{a}}$} & \multirow[b]{2}{*}{$t(h)$} & \multirow[b]{2}{*}{$X_{\max }(\%)^{b}$} & & \multirow[b]{2}{*}{$\mathrm{H}_{2} \mathrm{O}_{2}$ Eff.(\%) } \\
\hline & & & & Epoxide & Glycol & $\mathrm{MGE}^{\mathrm{c}}$ & \\
\hline Ti-ITQ-39 & 7.21 & 3.5 & 19.2 & 56.1 & 15.7 & 28.2 & 31.0 \\
\hline Ti-Beta & 9.34 & 2 & 19.6 & 43.7 & 0,0 & 56.3 & 51.0 \\
\hline TS-1 & 1.81 & 7 & 18.9 & $>98.0$ & 0,0 & 0.0 & 28.0 \\
\hline
\end{tabular}

Table 3: Oxidation of 1-hexene with $\mathrm{H}_{2} \mathrm{O}_{2}$ in acetonitrile over different titanosilicates

\begin{tabular}{|c|c|c|c|c|c|c|c|}
\hline \multirow[b]{2}{*}{ Catalyst } & \multirow[b]{2}{*}{$r_{0}\left(\mathrm{~mol}_{\text {conv }} / \mathrm{h} \cdot \mathrm{mol}_{\mathrm{Ti}_{\mathrm{i}}}\right)^{\mathrm{a}}$} & \multirow[b]{2}{*}{$t(h)$} & \multirow[b]{2}{*}{$X_{\max }(\%)^{b}$} & \multicolumn{3}{|c|}{ Selectivity (\%) } & \multirow[b]{2}{*}{$\mathrm{H}_{2} \mathrm{O}_{2}$ Eff.(\%) } \\
\hline & & & & Epoxide & Glycol & Enol & \\
\hline Ti-ITQ-39 & 15.98 & 3.5 & 14.2 & $>98.0$ & 0.0 & 0.0 & 17.7 \\
\hline Ti-Beta & 36.87 & 1 & 19.6 & $>98.0$ & 0.0 & 0.0 & 33.5 \\
\hline TS-1 & 0.54 & 5 & 18.0 & $>98.0$ & 0.0 & 0.0 & 40.9 \\
\hline
\end{tabular}


Table 4: Oxidation of cyclohexene with $\mathrm{H}_{2} \mathrm{O}_{2}$ in acetonitrile over different titanosilicates

\section{Selectivity (\%)}

\begin{tabular}{|c|c|c|c|c|c|c|c|}
\hline Catalyst & $r_{0}\left(\mathrm{~mol}_{\text {conv }} / \mathrm{h} \cdot \mathrm{mol}_{\mathrm{Ti}}\right)^{\mathrm{a}}$ & $t(h)$ & $X_{\max }(\%)^{b}$ & Epoxide & Glycol & Enol & $\mathrm{H}_{2} \mathrm{O}_{2}$ Eff.(\%) \\
\hline Ti-ITQ-39 & 54.85 & 1 & 23.9 & 44.0 & 8.0 & 48.0 & 47.0 \\
\hline Ti-Beta & 15.00 & 2 & 25.6 & 59.8 & 7.0 & 33.2 & 51.0 \\
\hline TS-1 & 3.68 & 3.5 & 26.3 & 22.7 & 0.0 & 77.3 & 57.0 \\
\hline
\end{tabular}


[1] J. Kärger, D. M. Ruthven, Diffusion in Zeolites and Other Microporous Solids; Wiley: New York, 1992.

[2] (a) J.L. Paillaud, B. Harbuzaru, J. Patarin, N. Bats, Science 2004, 304, 990; (b) A. Corma, M.J. Diaz-Cabanas, F. Rey, S. Nicolopoulus, K. Boulahya, Chem. Commun. 2004, 12, 1356; (c) A. Corma, M.J. Diaz-Cabañas, J.L. Jorda, C. Martinez, M. Moliner, Nature. 2006, 443, 842; (d) R.F. Lobo, M. Pan, I. Chan, H. Li, R.C. Medrud, S.I. Zones, P.A. Crozier, M.E. Davis, Science 1993, 262, 1543; (e) D.L. Dorset, S.C. Weston, S.S. Dhingra, J. Phys. Chem. B. 2006, 110, 2045; (f) R.F. Lobo, M.E. Davis, J. Am. Chem. Soc. 1995, 117, 3766; (g) M Moliner, T. Willhammar, W. Wan, J. González, F. Rey, J.L. Jorda, X. Zou, A. Corma, J. Am. Chem. Soc. 2012, 134, 6473; (h) R. Simancas, D. Dari, N. Velamazán, M.T. Navarro, A. Cantín, J.L. Jordá, G. Sastre, A. Corma, F. Rey, Science 2010, 330, 1219.

[3] A. Corma, M.E. Davis, V. Fornes, V. Gonzalez-Alfaro, R. Lobo, A. V. Orchilles, J. Catal. 1997, 167, 438.

[4]S. Inagaki , K. Takechi, Y. Kubota, Chem.Commun. 2010, 46, 2662.

[5] T. Willhammar, J. Sun, W. Wan, P. Oleynikov, D. Zhang, X. Zou, M. Moliner, J. Gonzalez, C. Martinez, F. Rey, A. Corma, Nat. Chem. 2012, 4, 188.

[6] (a) B. Notari, Adv. Catal. 1996, 41, 253; (b) R.J. Saxton, Topics Catal. 1999, 9, 43. [7]M. Tamarasso, G. Perego, B. Notari,US Patent, 1983, 4410501.

[8] (a) M.A. Camblor, A. Corma, A. Martinez, J. Perez-Pariente, J. Chem. Soc., Chem. Commun. 1992, 589; (b) J.C. van der Waal, P.J. Kooyman, J.C. Jansen, H. van Bekkum, Microporous Mesoporous Mater. 1998, 25, 43.

[9] T.Tatsumi, N. Jappar, J. Phys. Chem. 1998, 102, 7126.

[10] P. Wu, T. Komatsu, T. Yashima, J. Phys. Chem. 1996, 100, 10316.

[11] M.J. Diaz-Cabañas, L.A. Villaescusa, M.A. Camblor, Chem. Commun. 2000, 761.

[12] (a) P. Wu, T. Tatsumi, T. Komatsu, T. Yashima, J. Phys. Chem. B. 2001, 105, 2897;

(b) P. Wu, T. Tatsumi, Chem. Commun., 2002, 1026.

[13]M. Moliner, P. Serna, A. Cantin, G. Sastre, M.J. Diaz-Cabañas, A. Corma, J. Phys. Chem. C. 2008, 112, 19547.

[14]C.B. Dartt, M.E. Davis, Appl. Catal. A. 1996, 143, 53.

[15] Y. Kubota, Y. Koyama, T. Yamada, S. Inagaki, T. Tatsumi, Chem. Commun. 2008, 6224.

[16]M. Moliner, J. Gonzalez, M.T. Portilla, T. Willhammar, F. Rey, F.J. Llopis, X. Zou, A. Corma, J. Am. Chem. Soc. 2011, 133, 9497.

[17](a) A. Corma, M.E. Domine, L. Nemeth, S. Valencia, Nature. 2001, 412, 423; (b) M. Moliner, Y. Roman-Leshkov, M.E. Davis, Proc. Natl. Acad. Sci. USA 2010, 107, 6164; (c) M.S. Holm, S. Saravanamurugan, E. Taarning, Science 2010, 328, 602.

[18](a) T. Blasco, M.A. Camblor, A. Corma , P. Esteve, A. Martínez, C. Prieto, S. Valencia, Chem. Commun. 1996, 2367; (b) U. Wilkenhöner, G. Langhendries, F. van Laar, G.V. Baron, D.W. Gammon, P.A. Jacobs, E. van Steen, J. Catal. 2001, 203, 201. [19]M.A. Camblor, A. Corma, J. Perez-Pariente, Zeolites 1993, 13, 82. [20](a) A. Corma, M. Moliner, A. Cantín, M.J. Diaz-Cabañas, J.L. Jorda, D. Zhang, J. Sun, K. Jansson, S. Hovmöller, X. Zou, Chem. Mater. 2008, 20, 3218; (b) J.S. Reddy, R. Kumar, Zeolites. 1992, 12, 95. 
[21] A. Zecchina, G. Spoto, S. Bordiga, A. Ferrero, G. Petrini, G. Leofanti, M. Padovan, Stud. Surf. Sci. Catal. 1991, 69, 251.

[22] S.I. Zones, S-J. Hwang, S. Elomari, I. Ogino, M.E. Davis, A.W. Burton, C. R. Chimie, 2005, 8, 267.

[23] (a) A. Corma, P. Esteve, A. Martinez, S. Valencia, J. Catal. 1995, 152, 18; (b) A. Corma, M.T. Navarro, J. Perez-Pariente, J. Chem. Soc., Chem. Commun., 1994, 147.

[24] I.W.C. Arends, R.E. Sheldon, Top. Catal. 2002, 19, 133.

[25] A. Corma, M.A. Camblor, P. Esteve, A. Martinez, J. Perez-Pariente, J. Catal. 1994, $145,151$. 